\title{
TESTIMONIO
}

\section{DON SILVIO ZAVALA Y LA PIEL DEL HISTORIADOR. APUNTES SOBRE HISTORIOGRAFÍA MARGINAL}

\author{
Salvador Rueda Smithers \\ Museo Nacional de Historia, Castillo de Chapultepec
}

al vez los momentos menos predecibles de la vida de
don Silvio Zavala en su papel de director del Museo Nacional de Historia fueran cuando el destino y las exigencias de la historiografía como arma política lo encadenaron a una serie de hechos que comenzaron el 17 de septiembre de 1823. Ese lejano día inicial del México independiente, un grupo de patriotas republicanos contrarios al emperador Iturbide apoyaron el nombramiento de beneméritos a los héroes insurgentes y que se llevaran sus restos a catedral; eso significaba que los independentistas tendrían una genealogía que se remontaba a Hidalgo, Allende, Aldama, Jiménez, Morelos y Matamoros, y no dejarían solo a Iturbide en el papel de libertador ni al 27 de septiembre como día conmemorativo oficial del nacimiento de México. El asunto, por supuesto, no caía nada bien al emperador. Y quizás todo debió resolverse en los territorios del debate coyuntural, sin trascender a los extraños episodios de historiografía marginal que tocan las biografías de Silvio Zavala y de poco 
más de una decena de historiadores, antropólogos, arqueólogos y escritores entrelazados en la guerra de las imágenes emblemáticas de las identidades mexicanas.

Pero no fue así. Antes de cumplir su primer aniversario como nación independiente de España, diputados, periodistas, militares y los miembros del poder Ejecutivo tuvieron que enfrentar a los antiguos referentes de la memoria novohispana. La víspera del día de San Hipólito, y al recuerdo del añoso festejo del Pendón, que conmemoraba la conquista, un diputado llevó a la discusión el valor negativo de la sujeción colonial y, por extensión, de su momento primigenio, la caída de Tenochtitlan. A partir de entonces, tímidamente y más como un acto de contrición, se mencionó el carácter de antihéroe de Hernán Cortés.

Las palabras fueron eficaces por la necesidad de construir a los héroes propios de una nación que rompía con su pasado. De este modo, un año después volvería a apelarse al demonio de la historia. El 19 de julio de 1823, se aprobó el dictamen de la Comisión de Premios, con el propósito de cargar de símbolos históricos a un país que buscaba rehacer su memoria. Lucas Alamán escribió al respecto:

Buenos y meritorios los servicios hechos a la patria en los once primeros años de la Guerra de Independencia y beneméritos en grado heroico a Hidalgo, Allende, Juan Aldama, Abasolo, Morelos, Matamoros, don Leonardo y don Miguel Bravo, don Hermenegildo Galeana, Jiménez, Francisco Javier Mina, Moreno y Rosales: mandáronse escribir sus nombres en letras de oro en el Salón de Sesiones del Congreso; levantaron monumentos a su memoria en los lugares en que fueron ejecutados; y exhumaron sus cadáveres en los casos en que pudieron ser hallados, 
para ser conducidos a México, haciéndoseles, el 17 de septiembre, un magnífico funeral en la catedral, a cuya pompa concurrieron muchos de quienes los habían hecho fusilar. ${ }^{1}$

En esta construcción de signos, los antiguos realistas perdieron una batalla política. Junto con el regreso de Iturbide a su proporción humana y el desconocimiento del 27 de septiembre como fecha conmemorativa oficial de la independencia, la mayoría insurgente del Congreso declaró

[...] beneméritos de la Patria a los primeros caudillos independentistas; sus restos fueron depositados en una ceremonia que reflejaba el tamaño del desagravio que los responsables de cimentar la nación sentían ineludible para los héroes fundacionales. Se les depositó en el altar de los Reyes de catedral el 17 de septiembre de aquel año de 1823, a la vez que las cenizas de Hernán Cortés eran extraídas de su sepulcro por los representantes de sus herederos y con la cooperación honrosa del gobierno, a consecuencia de las excitaciones que a la plebe se hacían para que tomase en inofensivas cenizas venganza tardía si no ridícula. ${ }^{2}$

Pero no faltó el pretexto incendiario, según relató Arias: se recalentaron viejos odios con el conocimiento público de algunas decisiones políticas en España. Así, las Cortes españolas declararon nulos los convenios entre españoles y los gobiernos americanos independizados, capítulo final del desmoronamiento del imperio de Fernando VII. Diez días

${ }^{1}$ Alamán, Historia de Méjico, t. V, p. 711. Véase también Serrano MiGALLÓN, El Grito de Independencia, pp. 59 ss.

2 Arias, México a través de los siglos, t. VII, p. 206. 
después de la intentona punitiva contra los restos de Cortés, el comandante en Ulúa - último reducto colonial - disparó contra Veracruz; diez meses después, Iturbide sería fusilado. La biografía simbólica de Cortés cambió de signo violentamente. En esa misma generación, hombres comprometidos con la independencia, ya habían participado antes de los rituales conmemorativos de la conquista como gesta fundadora; en 1822 y 1823 trastocaron su solemnidad en hostilidad. Así, por ejemplo, la primera semana de julio de 1794, se efectuó el sexto traslado de los restos de Cortés en esta ocasión de la iglesia de San Francisco a la de Jesús Nazareno, anexa al Hospital de Jesús; el día 8 de julio "se hicieron las honras fúnebres en las que presidió, por más de tres cuartos de hora, un fraile que se haría después famoso: fray Servando Teresa de Mier". 3

A partir de la declaración de independencia los signos de la memoria cambiarían.

Todo lo que recordaba la secular dominación se deturpaba; no se quería ni que hubiese memoria de ella, y los legisladores mandaron abolir los títulos y dones de Castilla, borrar los escudos y los emblemas de esos títulos y picar las armas esculpidas de los Reyes españoles, de la Inquisición y de los tribunales, que en templos y edificios públicos todavía ostentaban las fachadas de los palacios, las torres, los acueductos y toda clase de monumentos". ${ }^{4}$

Fue entonces cuando se removió la estatua ecuestre de Carlos IV de Manuel Tolsá y se trasladó al patio de la

${ }^{3}$ Citado por Maza, “Los restos de Hernán Cortés”, p. 163.

${ }^{4}$ González Obregón, México viejo y anecdótico, pp. 214-215. 
Universidad, "no faltando antes de esto un imbécil que sugiriese la idea de fundirla para acuñar monedas", escribió Luis González Obregón. ${ }^{5}$ En este ambiente tan preocupado por las fechas y una memoria histórica que debía refundarse se propuso "que se quitaran los huesos de Cortés y demás insignias de nuestros opresores, del templo de Jesús", junto con el estandarte, "para olvidar el ominoso recuerdo de la conquista”. El padre Servando Teresa de Mier, tratando de evitar el desmán que esa propuesta extrema tenía aparejado, pidió que el estandarte y la inscripción se guardaran "como monumentos de antigüedad que siempre eran recomendables para perpetuar la memoria de los hechos, aun cuando éstos no hubiesen sido favorables". ${ }^{6}$ Es interesante notar la evolución política de los personajes involucrados en todo este episodio genésico de la idea de historia patria. El mismo padre Mier, antiguo apologista de Cortés tres décadas antes, hacía notorio el cambio en 1822: "El doctor don Servando de Mier escritor célebre, descendiente del último emperador de México, Quautemoczin [...] Esta es la verdadera causa porque se me desterró a España hace 25 años y no se me dejó volver [...]".

En 1823, con motivo del traslado de los restos de los insurgentes a la catedral metropolitana, se "despertó nuevamente el recuerdo poco grato de los dominadores, a lo cual contribuyó más la publicación de varios impresos que referían las crueldades de la conquista”, en los que se excitaba al pueblo a quemar los restos de Cortés en San Lázaro

\footnotetext{
${ }^{5}$ González Obregón, México viejo y anecdótico, p. 215.

${ }^{6}$ González Obregón, México viejo y anecdótico, p. 215.

7 Citado por Brading, Orbe Indiano. Mier, Historia de la revolución, t. II, p. 30, y Memoria político instructiva.
} 
(pp. 215-216). Una figura oratoria empleada en el discurso cívico de aquel año acabó de alarmar a los que abrigaban esos exagerados temores, pues en el calor de la perorata se pedía que "un rayo del cielo cayese sobre la tumba de Cortés", y el "rayo retórico" no destruyó el sepulcro, pero sí espantó a las personas tímidas encargadas de vigilarlo, quienes procedieron desde luego a "hacer desaparecer del todo el sepulcro, que había quedado cubierto después de sacadas las cenizas que contenía". ${ }^{8}$

"Fueron unos cuantos escritores, y una metáfora imprudente, lo que engendró la idea de hacer desaparecer el sepulcro, y éste desapareció a manos de sus tímidos guardianes $[\ldots . .]^{\prime}{ }^{9}$

"El choque de los huesos de conquistador con huesos insurgentes era inevitable”, escribió Francisco de la Maza un siglo más tarde, al ensayar una explicación de las causas del "descubrimiento" de los restos del conquistador en noviembre de 1946. También era previsible el desenlace de tal encuentro de reliquias: en 1823 el ambiente se perfiló contra el antiguo héroe por obra de "oradores del momento, lanzando discursos calentados con insultos a Cortés”. En esos días circularon folletos con títulos tan novedosos como las costumbres que inauguraba la vida independiente: "El Pendón se acabó y la memoria de Cortés quedó"; o "Muerte y entierro de don Pendón"; o "Los curiosos quieren saber en qué paran los huesos de Cortés". ${ }^{10}$ "Se pedía que los restos fuesen arrastrados por las calles y quemados en San Lázaro, lugar

8 Citado por Alamán, Disertaciones, t. II, pp. 59-60.

9 Alamán, Disertaciones, t. II, p. 219.

10 Citados por Maza, “Los restos de Hernán Cortés”, p. 164. 
donde la Inquisición prendía sus hogueras para los indios heterodoxos y homosexuales" - afirmó no sin un cierto abuso contrario a la precisión De la Maza. ${ }^{11}$

Volvamos al episodio de 1823. Mientras se colocaban los restos de los nuevos héroes en el Altar de los Reyes, se corrió el rumor de que se terminaría con el héroe más connotado de la Nueva España. Lucas Alamán escribió:

Los temores de que así se hiciese fueron tales y tan fundados [...] que el Sr. Provisor, a consecuencia de las contestaciones que tuvo con el Sr. Jefe Político, mandó al Capellán mayor del Hospital, Dr. D. Joaquín Canales, que en la noche que precedió al 16 de septiembre, procediese a sepultar en lugar seguro los huesos de Cortés, como lo verificó, habiendo yo intervenido en la pronta ejecución de estas órdenes en virtud de las funciones públicas que desempeñaba”. ${ }^{12}$

Trece años más tarde se hizo otra exhumación e inhumación de los restos del conquistador. El motivo, esta vez, era de índole moral. Francisco de la Maza conjeturó que a "don Lucas Alamán le dolía en secreto que los huesos de Hernán Cortés estuviesen en el suelo, con humedad y en sepulcro improvisado, por lo que decidió, en septiembre de 1836 trasladarlos a lugar más decoroso, aunque siguiesen todavía anónimos y ocultos". ${ }^{13}$

Que los contenidos simbólicos de las reliquias seguían el ritmo de la política, queda fuera de duda. De la Maza explica el sentido que tuvo, para Lucas Alamán, regresar a la iglesia

\footnotetext{
11 Maza, "Los restos de Hernán Cortés”, p. 164.

12 Maza, "Los restos de Hernán Cortés", p. 164.

${ }^{13}$ Maza, "Los restos de Hernán Cortés", p. 164.
} 
de Jesús y, volviendo a las coordenadas originales, mantener el secreto. De hecho, el movimiento, atestiguado ante notario, sería conocido por un grupo pequeño, "sin darlo a la luz a las masas ora patrióticas, ora desesperanzadas, ora vengativas, ora buscadoras de su identidad". Una larga nota de De la Maza deja claro el asunto - mismo que, con signo contrario, sería causa polémica y creadora de mitos y fraudes poco más de un siglo después-. De la Maza aventura que

[...] en septiembre de 1836 se gestaban dos hechos de suma importancia para don Lucas Alamán: el reconocimiento de la Independencia de México por España con el establecimiento de relaciones amistosas entre las dos naciones y la vuelta del destierro de su amigo, el futuro presidente por segunda vez, don Anastasio Bustamante. En el primer caso Alamán se congraciaba personalmente con la Madre Patria y no le daba al Embajador, que pronto vendría, el triste espectáculo de ver a Cortés pudriéndose en el suelo. En el segundo aseguraba la respetabilidad del nuevo entierro con la presencia en el poder de uno de los personajes más conspicuos del partido conservador. Recuérdese que en 1838 uno de los primeros actos de Bustamante fue traer a la ciudad de México, con gran solemnidad y en plan de glorificación, los restos de Agustín de Iturbide. Los hechos apuntados tuvieron efecto, el primero, el 28 de diciembre de 1836; el segundo, el 12 de abril de 1837. El sagaz Alamán se adelantaba, en todos los detalles, a la política que pronto debería sobrevenir. ${ }^{14}$

Poco más de un siglo más tarde, en 1945, el historiador José C. Valadés, conociendo el acta de Alamán, buscó los

${ }^{14}$ Maza, “Los restos de Hernán Cortés”, p. 166. 
huesos en la pared correcta de la iglesia pero no encontró nada: excavó unos $50 \mathrm{~cm}$ más abajo de lo debido. En 1946, el documento cambió de manos y llevó a los historiadores Carreño, De la Maza, Baeza y Moreno Fraginals a encontrar la tumba de Cortés: se trataba de un acta notariada, debidamente firmada por quienes participaron en ese regreso del suelo al nicho en 1836. Una copia quedó enterrada, resguardada por un tubo de plomo; otra más, la dio Lucas Alamán a la Embajada de España en 1843. De la Maza, Moreno y Baeza invitaron a Edmundo O'Gorman y a Alberto María Carreño para ayudar en las pesquisas. Sólo Carreño aceptó.

El 11 de noviembre nos reunimos en casa de Carreño para leer el documento. Cuando Baeza dio fin a la lectura, Carreño y yo nos convencimos de que aquel papel decía verdad. Era un acta notarial eclesiástica, cuyos firmantes eran personajes conocidos en la historia de México; además, la redacción y los detalles minuciosos confirmaban su autenticidad. ¿Qué hacer entonces? Sencillamente sacar los restos. Y sacarlos nosotros solos. ¿Por qué? Porque recurrir a una institución libre u oficial sería entorpecer, sobre todo en tiempo, la investigación; además ¿quién aseguraba que estaban todavía los restos en el lugar que explicaba el Expediente? Era necesario que la búsqueda fuera personal, rápida, audaz, sin reticencias protocolarias y, sobre todo, en secreto, ya que dado el caso que se fracasara, ni trascendía indebidamente, ni quedaba en ridículo la institución a la cual hubiéramos recurrido. ${ }^{15}$

El descubrimiento fue un éxito periodístico, como siempre que se tocaba el asunto de las reliquias de personajes

${ }^{15}$ Maza, “Los restos de Hernán Cortés”, p. 169. 
fundacionales. Apareció la caja, envoltorio, huesos y papeles que daban testimonio, no de que fueran los restos de Cortés, sino de que esos fueron los que Alamán enterró como de Cortés. Los huesos, además, mostraban signos de deterioro en vida. Por supuesto, se organizó una comisión y se ordenó un estudio histórico, osteológico y de antropología física, para determinar la autenticidad de los restos como de Cortés, así como sus características personales a la hora de morir. En principio, una copia del documento depositado por Alamán fue solicitado oficialmente por Silvio Zavala, director del Museo Nacional de Historia y por ello miembro de la Comisión del InAH, a la Embajada de la República Española en 1946, a fin de hacer el cotejo y el examen histórico de su autenticidad. El cotejo resultó positivo, no sin un cierto desorden, causado por la importancia que los periodistas dieron al descubrimiento. De la Maza recordaría que fue

[...] inútil querer, por parte de los miembros del Instituto [Nacional de Antropología e Historia], que hubiese orden y decoro. Ante cientos de curiosos se abrió la urna de cristal en busca del documento que confirmaba la autenticidad de los restos. Don Alberto María Carreño, el doctor Benjamín Trillo y el doctor Daniel F. Rubín de la Borbolla, oficiaron. Cuando el tubo apareció, se designó al doctor Silvio Zavala, como director del Museo de Historia, para que leyese el documento. Carreño pidió a la concurrencia que fuese él quien diera lectura. Silencio absoluto. Y lo leyó. ${ }^{16}$

La nota periodística de Jacobo Dalevuelta, jefe de información de El Universal (29 nov. 1946), describe el suceso

16 Maza, “Los restos de Hernán Cortés”, pp. 171-172. 
que atestiguaron el 24 y 25 de noviembre. Dalevuelta entrevistó brevemente a Silvio Zavala. Permítaseme reproducir lo que los lectores del diario leyeron el 29 de noviembre:

${ }_{-}$¿Cree usted que la prueba a que asistimos sea concluyente?

- La prueba documental es irrecusable - contestó.

- ¿Puede usted afirmar que no haya lugar a duda acerca de la autenticidad de los restos?

- Yo creo que sí son; pero no lo afirmaré definitivamente, hasta después de que se hayan hecho los estudios científicos necesarios.

Era sensata esa opinión, pues no se trata aquí de un juego o de una cuestión baladí. Todo el mundo se interesa en estos momentos por el descubrimiento más sensacional del siglo, en materia de Historia. ${ }^{17}$

El caso del estudio de los huesos, en fin, fue turnado a los más afamados especialistas del Instituto Nacional de Antropología e Historia, encabezados por Eusebio Dávalos, quienes tiempo después emitieron su dictamen: se trataba de un individuo de 1.58 de estatura, empequeñecido por la edad y con afecciones serias (osteítis y osteosis) de origen no infeccioso: el hombre padecía raquitismo de anciano al morir. Concordaba esto con las descripciones de Hernán Cortés: hombre de aproximadamente 1.60 de estatura, con una lesión en un brazo; murió a los 63 años. Al terminar el peritaje, se decidió regresar los restos al lugar de su tumba.

Por su parte, el criminalista más influyente del momento, Alfonso Quiroz Cuarón, decidió emitir otro peritaje, habiendo revisado las fotografías de los huesos. Su dictamen

17 Citado por Carreño, “Hernán Cortés”, p. 388. 
desmentía el de los antropólogos físicos, pero aunque remitía a una petición de principio - afirmó que actuaba con toda pulcritud científica - tenía el defecto de no haber revisado el objeto de su análisis sino sus imágenes fotográficas. La conclusión de Francisco de la Maza resultó profética, pero a la inversa. Escribió entonces que hay

[...] que hacer notar que, por la forma independiente y personal en que se hizo el descubrimiento, se destruyó una simulación, un mito histórico que traía inquietos desde hace cien años a los aficionados a estas cosas. Esta simulación ha estado sostenida por instituciones y personas interesadas en ello. Los huesos de Cortés serían, en un momento oportuno, un símbolo. Quienes sabían dónde estaba enterrado y no lo habían sacado era porque esperaban "la mejor ocasión”, pero ¿la mejor ocasión de qué? De servirse de la bandería cortesiana, del símbolo que representa o pudiera representar, en un momento dado, la figura de Hernán Cortés. Ahora ya no es posible. El mito se ha deshecho. ${ }^{18}$

Profecía a la inversa, porque faltaba un capítulo todavía. Era enero de 1949. La descripción de los restos y la enfermedad senil de Cortés ya no parecían importantes para ningún mexicano, excepto para los hispanistas, y quizás para un lector interesado en el dictamen de Quiroz Cuarón: Diego Rivera, quien ya había decidido pintar a Cortés como un sifilítico deforme; la contienda presidencial de 1952 comenzaba, de manera sorda, ese mismo año de 1949. Y los muros deberían atajar el regreso de los conservadores.

18 Carreño, “Hernán Cortés”, p. 173. 
No habría coincidencia sino lógica: la lógica de la conspiración. Apenas un mes después de la resolución de Quiroz Cuarón y de su contundente dictamen sobre los restos de Hernán Cortés y sus alegatos ideologizados con el ropaje del vocabulario científico, El Universal publicó una nota que abriría la llaga sobre las raíces del México heroico. Fechada el 7 de febrero de 1949, desde Teloloapan, se dijo que "un señor apellidado Rodríguez, vecino de Ixcateopan, encontró un importantísimo documento del padre Motolinía, según el cual se pretende haber localizado el sitio en que fue sepultado Cuauhtémoc". ${ }^{19}$

El 17 de febrero, después de una presión periodística más o menos fuerte - como la que sintieron los descubridores de los restos de Cortés en noviembre de 1946- y quizás ante la más poderosa insistencia del gobernador de Guerrero, general Baltasar Leyva Mancilla, la conocida historiadora y arqueóloga, Eulalia Guzmán, fue comisionada por el INAH para ir a Ichcateopan y rendir un informe sobre el asunto. La lista de los documentos que motivaron el viaje de la profesora Guzmán, cuatro con la supuesta firma de Motolinía, llamaban a la incredulidad:

-El libro Destierro de ignorancias, publicado en la segunda mitad del siglo xviII, con anotaciones al márgen y la firma imaginaria de Motolinía.

- Documentos varios, también con la firma de Motolinía.

- Carta pastoral del arzobispo Núñez de Haro y Peralta, publicada en México en 1777.

- Cartas eruditas de Feijoó.

${ }^{19}$ Citado por RuedA, “De conspiradores y mitógrafos”, pp. 17-26. 
-Expediente de un pleito entre el pueblo de Ichcateopan y la hacienda de Zacatlán.

- Cuadernos de Florentino Juárez, abuelo de Salvador Rodríguez Juárez, entre ellos uno denominado "Instrucciones de Dn. Florentino Juárez a sus hijos al dejarles en guarda los documentos referentes a Cuauhtémoc".

Forma y contenido de los documentos, en conjunto y uno por uno, apuntaban a una falsificación. Con seguridad Eulalia Guzmán lo supo desde la primera mirada; sin embargo, no se pronunció nunca en su contra. De hecho, sin descalificarlos, la profesora Guzmán estableció una ruta de investigación y organizó la posible polémica con el historiador Salvador Toscano, también del INAH, y que entonces preparaba una biografía de Cuauhtémoc - biografía que podemos conjeturar ahora no sería una apología más del panteón celebratorio nacional, sino un estudio de iconografías y análisis de códices y crónicas-. En septiembre, siguiendo las indicaciones de los papeles de Florentino Juárez, la comisionada del INAH mandó derribar el altar de estilo neoclásico de Santa María de la Asunción. Después de levantar el acta correspondiente y hacer algunas calas, encontró los restos de varios sacerdotes enterrados en el interior del templo. Sin darse por vencida, en otra cala, a medio metro de profundidad, encontró varias piedras amontonadas; ordenó que las levantaran. El acta del día asentó el prodigio:

[...] apareció una placa ovalada de cobre en declive hacia el Este, a medio enterrar en una tierra carbonosa, que contenía en su mayor parte fragmentos de hueso calcinado [...] Sacada la placa, se distinguió sobre la superficie gris una cruz y al pie de ésta la inscripción 1525-1529 Rey é S Coatemo. Abajo del 
óvalo, atravesada de NE a SO, estaba una punta de lanza, de cobre. $^{20}$

El 26 de septiembre de 1949, Eulalia Guzmán declaró públicamente haber descubierto la tumba de Cuauhtémoc. Horas después, valga la acotación al margen, el destino clausuraría las posibilidades de polémica sobre los rasgos de la biografía simbólica del último tlatoani: Salvador Toscano, el estudioso que pudo poner en duda la posibilidad de que Cuauhtémoc de Ichcateopan fuese necesariamente el tlatoani mexica, moriría en un accidente aéreo en el Popocatépetl. Serían otros, entre ellos el director del Museo Nacional de Historia, Silvio Zavala, los encargados de desenmascarar la impostura como miembros de una Comisión Dictaminadora de los hallazgos de Ichcateopan. Al igual que en el suceso de la iglesia de Jesús Nazareno, los de la iglesia de Santa María de la Asunción harían correr tinta en la prensa escrita. Pero esta vez tomaría sabores amargos entre sus participantes.

Una fotografía de 1950 nos descubre los propósitos de los estudiosos reunidos en Ichcateopan en torno a Eulalia Guzmán. Se armaba, o se quiso armar, el léxico plástico que describía a los protagonistas de la historia patria: Cuauhtémoc y, por obra del dictamen de Quiroz Cuarón, Hernán Cortés. La intención no debió extrañar. Diego Rivera era sin duda un genio del lenguaje. Armado de papel y carbón, frente a un esqueleto magramente organizado - hoy sabemos que utilizó poco más de un centenar de huesos, depositados en la tumba bajo el altar mayor de la Iglesia de Santa

${ }^{20}$ El hallazgo de Ichcateopan, citado por RuEDA, "De conspiradores y mitógrafos”, p. 20. 
María de la Asunción de Ichcateopan, pertenecientes a más de cinco personas-, Rivera dibujó la silueta de un individuo robusto, de cerca de 1.75 de estatura. El estudio de los dientes y la fortaleza de algunos huesos escogidos se ajustaban a la imagen preconcebida por el artista: se trataba de un hombre de alrededor de 25 años de edad al momento de su muerte, con una seria lesión en el pie, según se pensó al ver las marcas de cicatrización en un calcáneo deforme, y que se dijo pudo ser resultado de una quemadura severa. Lo importante era su proporción estética, a pesar de reiteradas declaraciones sobre la búsqueda de la verdad histórica y el respeto a la objetividad científica. Proporción estética: fornido, más alto y de mejor presencia que su victimario histórico, Hernán Cortés. Cuauhtémoc, primer héroe del nacionalismo mexicano y último tlatoani mexica, reescribía en Ichcateopan el último capítulo del mundo prehispánico que interrumpió la larga noche colonial, según veían sus inventores Rivera, Quiroz Cuarón, Eulalia Guzmán, Luis Chávez Orozco y una decena más de estudiosos.

Pues Diego Rivera, Alfonso Quiroz Cuarón y Eulalia Guzmán conspiraban. Lograr la aceptación de la imagen armónica de Cuauhtémoc era parte de una tarea tan urgente como compleja: las fatigas del criminalista Quiroz Cuarón y del pintor Diego Rivera se dirigían a la recreación de la historia nacional - tarea de Eulalia Guzmán-, a la refundación de sus mitos y a la construcción visual de sus héroes $-\mathrm{y}$ de paso de sus villanos-. El hecho histórico y el hecho estético serían, entonces, los pilares de una historia que conciliaba la dureza de un pasado trágico con el presente de un país prometedor. La tarea no era menor. Se buscaba estructurar los signos conocidos con los recientemente inventados, 
de historias intachables con las conjeturas novedosas. Se trataba del mito moderno de la patria.

A Silvio Zavala le tocó la tarea de revisar la autenticidad de los documentos que fueron el origen del descubrimiento de los restos bajo el altar de Santa María de la Asunción. En su informe final, Zavala explicó propósitos y metodología:

[...] procedí a realizar el estudio de los manuscritos e inscripción, y de algunas circunstancias históricas relacionadas con el hallazgo, pues de los documentos de Ichcateopan resultaba que el entierro de Cuauhtémoc en este lugar era atribuido al padre Motolinía, cuyo nombre aparecía al calce de cuatro de los textos hallados. [...] El alcance de la respuesta que se obtuviera en relación con estas dudas podía ser, a mi juicio, el siguiente: a) Si los documentos corresponden al siglo xvi y particularmente a Motolinía, habría una fuerte prueba a favor de la autenticidad del relato acerca del entierro. b) Si la placa de metal guardara correspondencia con los documentos, y fuese también del siglo xvi, no cabría duda acerca de que el entierro hallado era el señalado en los documentos. c) Si el carácter de los restos hallados coincidiese con los datos históricos que conocemos acerca de Cuauhtémoc, la autenticidad del hallazgo se convertiría en humana certeza.

También, por supuesto y como anotó Zavala, que nada correspondiera, por lo que habría que explicar el porqué de la impostura, su autor y el momento de la invención. ${ }^{21}$

El reto para Silvio Zavala no era descubrir si se trataba de una falsificación, sino de convencer a los lectores de

${ }^{21}$ El hallazgo de Ichcateopan. Dictamen, 1950, Zavala, “Dictamen”, pp. 226-227. 
las formas que asumía. No tuvo dudas: fue Florentino Juárez, nacido en 1842 y muerto al principiar 1915, el autor de documentos y tumba hacia el mediodía porfiriano. Escribió que el "grandilocuente estilo cívico del siglo xix inflama a este hombre de la apartada sierra guerrerense". Hombre movido por un amor patriótico tan profundo como su ingenuidad - al hacer firmar a Motolinía en documentos del siglo XVIII-. Entonces Zavala comenzó su propio y divertido descubrimiento, el del mitógrafo pueblerino, inteligente, entregado, misionero laico que buscó reencontrar raíces indígenas disueltas en la conquista. Sin quererlo, Silvio Zavala conectó a Florentino Juárez con los mitógrafos del Congreso en 1823: apuntó que es

[...] una actitud semejante a la que surgió en la historiografía mexicana inmediatamente posterior a la guerra de la independencia, cuando el retorno al indigenismo prehispánico constituía un medio para afirmar los valores de la incipiente nacionalidad; pero en el caso de don Florentino no puede afirmarse que esta postura sea tan sólo un tardío eco de aquella corriente intensa de la historiografía del siglo XIX, pues bien puede ocurrir que corresponda, en razón de la raza, la lengua y el ambiente indígenas mejor conservados en la apartada región donde vive, a un brote natural de tradiciones "mexicanas" que sobrevivieron a la conquista española. ${ }^{22}$

Don Silvio Zavala disfrutó su encuentro, ciertamente más enriquecedor por su contenido de inteligencia natural que el de los previsibles y nada convincentes protocolos políticos que obligaban a los historiadores a explicar que sus ideas no

${ }^{22}$ Zavala, “Dictamen”, pp. 252-253. 
eran juicios sobre personajes históricos - ya fuera Cortés, ya Cuauhtémoc-, con Florentino Juárez.

En el curso de esta penosa investigación, realizada en un ambiente de ligerezas y denuestos de toda especie, el hallazgo de este hombre vino a ser una grata compensación. Porque si el trabajo documental pasado, se asemeja más bien a un triste derrumbe, y mal puede avenirse con el consejo de Vasco de Quiroga que pedía obras non in destructionem sed in aedificationem, el que pudiéramos llamar descubrimiento de este historiador instintivo y poético nos trajo solaz y descanso y nos abrió un portillo para la valoración positiva del extraño episodio que estudiamos.

Don Florentino brota de la tierra y del pueblo de México. No es fruto de letras ni del medio urbano. Se forma en la soledad lugareña, viaja por el ámbito al parecer reducido pero humanamente rico de su región, se detiene ante todas las cosas que ofrecen algún valor natural, industrial, folklórico o histórico. Es un alma curiosa, sensitiva, abierta, que realiza milagros de imaginación y de expresión que parecen provenir de una cultura tradicional profunda, verdaderamente histórica, compleja como nuestro pueblo, donde un grupo de humildes labriegos de hoy vestidos de blanco, con "guaraches" y grandes sombreros, hereda sin saberlo la grandeza y el señorío de la antigua nobleza mexicana que antes gozó de hombres guerreros y supo imponer su dominación. El estudio se trueca, gracias a esto, en un descenso a las intimidades de la formación histórica del pueblo de México [...].23

Por supuesto, como todo polemista, ni Eulalia Guzmán y su grupo, ni Diego Rivera, aceptarían los resultados de la

23 Zavala, “Dictamen”, pp. 256-257. 
Comisión Oficial Dictaminadora. No lo hacían porque no se trataba de un debate científico, en el que la razón prevalecería por su carga de pruebas favorables; importaba otra cosa: los símbolos de la patria, que buscaban cerrar el círculo que comenzó en noviembre de 1946 con el descubrimiento de los restos de Cortés. Los polemistas no perderían la oportunidad.

Vale la pena apuntar una coincidencia más: en 1823 se borró el 27 de septiembre como fiesta oficial de conmemoración. A partir de 1949, el 27 de septiembre, el mito fundacional que remontaba a la conquista, sería enriquecido con elementos agregados: el héroe Cuauhtémoc dejaba de ser un oscuro tlatelolca al que las circunstancias de la guerra y la epidemia de viruela llevaron a encabezar la resistencia mexica durante el último capítulo del sitio de Tenochtitlan; su nueva biografía, completada por los datos aportados por los documentos de Ichcateopan, lo hacía casi un predestinado. Según éstos, el pudor de un fraile, Motolinía, y el rechazo secular de los indios a los explotadores españoles y sus descendientes, mantuvieron en resguardo privado esa "otra" parte de la historia, que ahora se abría al público. El secreto develado, con las sanciones políticas oficiales, podía entrar en la mitografía por el vehículo de la pintura: esa sería la tarea de Rivera. De tal manera se cerró el círculo plástico que, haciendo a un lado el dictamen de los antropólogos físicos que señalaban que las deformaciones de Cortés eran producto de su vejez, Rivera propondría un anacrónico Hernán Cortés siempre senil, sifilítico y monstruoso en el momento de enfrentar a sus atléticos oponentes indígenas. La imagen inventada por Alfonso Quiroz Cuarón fue retomada por Diego Rivera y trasladada, con estilo propio, 
a los murales de Palacio Nacional y del Teatro de los Insurgentes, facturados entre 1949 y 1951. Rivera y Quiroz Cuarón se tomaron la libertad, en su reconstrucción del mito de la historia patria, de castigar a los muertos - para robarle la frase, también de aquella época, a Edmundo O'Gorman-. El conquistador fue rebajado a un ser patológico y repugnante; como contraparte, Cuauhtémoc debía elevarse de la simple calidad humana tanto por el tamaño de su tragedia como por su tamaño estético.

La polémica, por supuesto, tuvo tonos agrios. Diego Rivera llegó a pedir, en un desplante que le era muy propio, que se fusilara por la espalda, acusados de traición a la patria, a quienes no aceptaban la tesis de la profesora Guzmán. Dolidos pero firmes, los miembros de la Comisión que declaró la impostura se sostuvieron e intentaron olvidar los ataques sufridos contra su ética profesional. El dictamen final de Silvio Zavala resume el sentimiento distanciador y la prudente delicadeza con que se manejó el asunto:

Creo que es oportuno separar con nitidez - escribió Zavalala admiración y el respeto que sentimos los mexicanos por la figura de Cuauhtémoc del problema netamente científico que consiste en establecer la autenticidad del hallazgo de los restos de Ixcateopan, logrado por Eulalia Guzmán con innegable tesón e indiscutible probidad, y apoyado con altura de miras y patriotismo por el culto gobernante del estado de Guerrero, Baltasar Leyva Mancilla.

Llamado a opinar en el caso en virtud de haber recibido una comisión oficial a ese respecto, pude examinar en Ixcateopan los documentos que se relacionan con el hallazgo, y mi impresión es que ni el contenido ni la letra de los documentos corresponden al siglo xvi. 
Esta impresión personal puede ser equivocada, ya que todos estamos expuestos a errar aun en asuntos de nuestra propia profesión, por lo cual, y dada la importancia del caso, creo que debiera recogerse la impresión de otros historiadores y paleógrafos para llegar a conclusiones que estén al margen de cualquier escrúpulo.

En el mecanoescrito de su dictamen, Zavala opinó que los documentos falsos fueron elaborados por Florentino Juárez entre finales del siglo xIX y principios del Xx. Además, se permitió una licencia que tachó para la versión impresa. El director del Museo Nacional de Historia se cuidó de no entrar en los terrenos de la polémica no historiográfica que buscaban Rivera, Quiroz Cuarón y Eulalia Guzmán. En su mecanoescrito se permitió el desahogo; en su versión impresa prevaleció el instinto de conservar intacta la piel del historiador - la que permitió a Polibio sobrevivir 2000 años antes - . La nota de Silvio Zavala diría así:

Gracias a esa potente y colorida imaginación, han quedado asociados a Ichcateopan tanto Cuauhtémoc como Motolinía y San Juan Clímaco [...] [y sospechamos que de no haber mediado el obstáculo cronológico, hubiera incluido también a Diego Rivera] y por inexcusable consecuencia otros nombres de nuestros días.

Como hemos podido ver en este ejercicio de conexiones, se ligan nombres de otras épocas en esta extraña historia de símbolos y mitografías. Más sentida es la última afirmación, sobre Florentino Juárez: "Ninguna de las obras históricas en lo que va de siglo ha conmovido a México como la de este 
virtuoso de la resonancia. Lo presentía y no se equivocó". ${ }^{24}$ Treinta y seis años después, una nueva Comisión interinstitucional y multidisciplinaria revisó documentos, huesos, edificios, tradición oral, contexto histórico y los pormenores del descubrimiento de Eulalia Guzmán. Participó en ella una generación nueva de estudiosos especialistas, entre quienes estaban Guillermo Bonfil, Arturo Romano, Eduardo Matos, Sonia Lombardo, Alejandra Moreno Toscano, Luis Reyes García, entre otros; representando al Museo Nacional de Historia, la historiadora Alicia Olivera encabezó al equipo que buscó los mecanismos de la tradición oral en torno al entierro de Cuauhtémoc. Al igual que en 1949-1950, la presión del gobierno del estado de Guerrero, el apoyo del presidente Luis Echeverría y alguna prensa apresuró las labores, pero no influyó en la respuesta de los científicos. Los resultados de 1976 fueron parecidos a los que ofreció la Comisión en 1950. Sólo cambió un nombre, el del responsable de la ficción: Silvio Zavala pensó que la falsificación de los documentos y la factura de la inverosímil tumba era obra de Florentino Juárez; Luis Reyes concluyó que fue Salvador Rodríguez Juárez, nieto de Florentino, partero y - hoy lo sabemos por las pesquisas de Ruth Arboleyda en los papeles históricos del INAH - empleado como inspector de monumentos en los años treinta, el autor de los documentos. Y se sospechó, como siempre, que la profesora Eulalia Guzmán inventó la tumba.

Permítaseme ensayar una conclusión a este escrito. Se trata de una relectura de cómo los historiadores estamos más que inmersos en los problemas de nuestros propios tiempos

${ }^{24}$ Zavala, “Dictamen”, p. 257. 
- no sólo los sociales y económicos o políticos, sino también los del debate intelectual - y cómo pareciera que el destino nos lleva de la mano. No quiero dejar de mencionar que la decisión de don Silvio Zavala me recuerda la de Polibio, según nos explica en su ensayo "La piel del historiador" el italiano Arnaldo Momigliano, pues Polibio necesitó de su inteligencia para sobrevivir a las violencias interesadas de sus contemporáneos. Creo que don Silvio la pensó dos veces antes de enfrentar a Diego Rivera y servirle de trampolín, pues Rivera no hubiera perdido la ocasión de medirse con un contrincante que le dejaría bastante publicidad. Un poco de razonable instinto de sobrevivencia. Don Silvio está en su centenario, lúcido; Polibio murió al caérsele el caballo encima cuando montaba; también lúcido, tendría 80 años. En fin, puedo terminar diciendo que esta experiencia de don Silvio Zavala es un ejemplo de las bifurcaciones que aparecen en el camino de las vidas profesionales de muchos historiadores: son capítulos marginales, pero que nos ligan con varias generaciones, desde Lucas Alamán hasta Silvio Zavala y Luis Reyes, desde Carlos María de Bustamante hasta Francisco de la Maza, desde Eulalia Guzmán a Diego Rivera, de Eusebio Dávalos y Quiroz Cuarón a Romano, de Alicia Olivera y Sonia Lombardo a Silvio Zavala, Salvador Toscano, Salvador Rueda y Salvador Rodríguez Juárez. El nudo de nombres es enorme. No son los únicos, por supuesto, envueltos en las extrañas corrientes que desatan los rumores, las conspiraciones y las falsificaciones al confrontarse con la verdad histórica. Baste recordar que no solo en Ichcateopan se falsificó a Motolinía; ya O’Gorman dio cuenta de que el responsable de la orden, presionado por el gobierno de Felipe II al mediodía del siglo xvi, falsificó la firma del fraile en una 
obra que, por sus equivocaciones, no podía ser de su mano. Pero también podemos pensar en fray Martín Durán, personaje inventado por Carlos María de Bustamante y copiado por Francisco Sosa, puesto en duda por José María Vigil y descartado por Joaquín García Icazbalceta; o en el cráneo de Morelos, que hacia principios del siglo xx llevó a un largo dictamen de Nicolás León y a determinar que se trataba de los restos del escultor Patiño Ixtolinque, por mencionar algunos.

Me refiero, por supuesto, a experiencias de destinos cruzados: me ha tocado participar en la Comisión Revisora de los Hallazgos de Ichcateopan de 1976, en el grupo que encabezó Alicia Olivera cuando estábamos - otra vez el destino - en el Museo Nacional de Historia, Castillo de Chapultepec. Como cabeza del museo, me ha tocado tratar de desenredar el misterio de los huesos de Morelos: menos interesante desde el punto de vista intelectual, a pesar de que, me temo, hará correr mucha tinta. Déjenme terminar con esta reseña, que amarra otra vez a 1823 y los restos de los héroes de la independencia.

El 6 de enero de 1895 nacía un semanario ilustrado que se publicaría los domingos para repartirse en los domicilios de los suscriptores; llevaría el nombre de El Mundo. Semanario Ilustrado. En su página inicial, con una gran fotografía del interior de la catedral, el semanario abría con una efeméride. Al hacer una reseña sobre el Altar de los Reyes con motivo de la Epifanía, el reportero de El Mundo describía la historia legendaria de los Reyes Magos y la belleza churrigueresca del altar. De paso, hizo notar el deplorable estado en el que se encontraba la cripta en la que se guardaban los restos de Hidalgo, Allende, Aldama, Jiménez, Mina, 
Morelos y algunos de los insurgentes declarados héroes en 1823, "cada uno de los cuales tiene las respectivas iniciales para distinguirlos”. Inquietó una pequeña observación al final de la página 1: "En el fondo del ataúd hay otros restos, todos en la imposibilidad de ser siquiera tocados porque están deshaciéndose".

El Mundo no quitó el dedo del renglón. En su número del 4 de agosto de 1895 informó que se tomaron algunas medidas para resguardar con cierta dignidad los restos de los héroes de la independencia. Se trató de una convocatoria eficaz:

Una visita que varias personas - entre ellas algunos periodistas - hicieron a las criptas húmedas y sombrías de Catedral, unos artículos publicados en los diarios de la capital y una iniciativa presentada en el seno de la corporación llamada "Gran Familia Modelo", a fin de que las sociedades mutualistas compraran una urna para guardar aquellos venerables despojos mortales, lograron despertar el recuerdo de que esas reliquias merecían otro lugar más digno que el que ocupaban, y de que, si bien la sociedad está dividida en grupos, más que por la política, por detalles de ritual eclesiástico, o por grados de fervor religioso [...] el pueblo entero está obligado, sin distinción de ideas y principios a honrar la memoria de quienes honraron a la patria al libertarla del dominio extranjero y proporcionarle las instituciones liberales que nos rigen.

El resultado fue la apertura de una suscripción para comprar una urna que costaría 350 pesos.

Luego de reseñar brevemente la llegada de los restos de los insurgentes en 1823, señala que no hubo cuidado en 
mantener las identidades personales de cada uno: "se reunieron en completa confusión", afirmó;

$[\ldots]$ con extraordinaria pompa fueron trasladados [...] a la iglesia de Santo Domingo, donde según se dice, al pretender separarlos el jefe político, los mezcló más de lo que estaban, a juzgar por el hecho de haberse encontrado entre los que se suponían de Mina, algunos de D. Pedro Moreno, que fue notable por su estatura gigantesca. ${ }^{25}$

De hecho, una etiqueta con una letra fue el único elemento de identidad y registro, confuso en sí mismo si atendemos, por ejemplo, que con la " $\mathrm{M}$ ” debieron estar los cráneos de Morelos, Matamoros, Mina y Moreno.

Como ya se había dicho en el seno del Cabildo y se había repetido en la prensa, los huesos enterrados en lugar muy húmedo, se encontraban en un estado deplorable: si hubieran permanecido allí pocos años más, sólo se hubiera ya encontrado polvo, pues verbigracia al tomar uno de los cráneos, casi se desbarató.

Extraídos de la cripta en uno de los últimos días de la semana pasada, fueron transportados al patio llamado "de los coloraditos", anexo a la Catedral, y colocados sobre una tosca tabla. Dos médicos y algunas otras personas procedieron entonces a limpiarlos, operación que ejecutaron sin ningún respeto, y tan burdamente, que, según se dice, rompieron entre sus manos, al lavarlos con estropajo y jabón común, algunos de aquellos fragmentos preciosos del cuerpo de nuestros libertadores. ${ }^{26}$

${ }^{25}$ El Mundo (4 ago. 1895), p. 8.

${ }^{26}$ El Mundo (4 ago. 1895), p. 8. 
Más que descuido, fue la ignorancia lo que atentó contra las reliquias.

Un pobre catafalco en que dos días yacieron esos huesos, expuestos al sol para que se blanquearan. Como si se hubiera tratado del cadáver de un mendigo, que apenas por caridad es amortajado, preciso fue que el sacristán regalara unos cirios y que un particular llevara unas banderas usadas y desteñidas para que esas reliquias tan acreedoras a toda clase de atenciones y cuidados, no reposaran sobre las carcomidas tablas en que estuvieron relegadas como guijarros sin valor ninguno. ${ }^{27}$

Luego de tan rudo trato, fueron depositadas en su urna de cristal con aplicaciones de oro y plata. Fue en este último traslado, entre el 27 y el 30 de julio de 1895 (aniversario luctuoso de Miguel Hidalgo y Costilla), cuando al no reconocer los pocos indicios de identidad - como las etiquetas con letras mayúsculas que señalaban el apellido del héroe a quien correspondía el grupo de huesos, o las botas y "lo que quedaba del capote” de José María Morelos-, se conjeturó que "habían desaparecido" y que era posible que Juan Nepomuceno Almonte se los hubiese llevado a París, donde estarían sepultados. El asunto volvió a ser tocado con cierto escándalo nuevamente en 1925 , cuando se trasladaron los restos de los héroes a la Columna de la Independencia. De nuevo, la pluma de Jacobo Dalevuelta desató a los demonios. No desaparecieron, pero se aplacaron. Una investigación moderna, encabezada por José Manuel Villalpando y Luis Reed, comprobó en 1991 que los huesos de Morelos no estaban en el cementerio del Pére-La Chaise, en el

${ }^{27}$ El Mundo (4 ago. 1895), pp. 8-9. 
sepulcro de Almonte. ${ }^{28}$ En 2006 otro periodista sacó a relucir la supuesta ausencia: con extraño asombro, dijo que el "Gobierno nos ha engañado", al enterarse del rumor de que Morelos no estaría en el monumento a la Independencia. Una nueva comisión, en la que participamos los historiadores José Manuel Villalpando, Víctor Ruiz Naufal, Amparo Gómez Tepexicuapan, Guadalupe Jiménez y quien esto escribe, buscó desentrañar el raro secreto. Fue entonces que pudimos ver, por medio de las fotografías de Cruces y Campa y de los hermanos Torres, "la revoltura de huesos y cráneos" que formaron el indeseado osario. Los restos de Morelos, como los de Cortés, Cuauhtémoc y la decena de insurgentes, cumplen en silencio su destino natural donde quiera que estén. Tal vez no deba ser de otra manera. Polvo son, como polvo seremos todos.

\section{REFERENCIAS}

Alamán, Lucas

Historia de Méjico, México, Imprenta de J. M. Lara, 1852, t. V. Disertaciones, México, Jus, 1969, t. II.

Arias, Juan de Dios

México a través de los siglos, México, Cumbre, 1956, t. VII.

Brading, David

Orbe Indiano. De la monarquía católica a la república criolla, 1492-1867, traducción de Juan José Utrilla, México, Fondo de Cultura Económica, 1991.

${ }^{28}$ Reed Torres y Villalpando César, Los restos de Don José María Morelos y Pavón. 
Carreño, Alberto María

"Hernán Cortés y el descubrimiento de sus restos", en $\mathrm{Me-}$ morias de la Academia Mexicana de la Historia, t. VI, núm. 4 (oct.-dic. 1947).

El hallazgo de Ichcateopan

El hallazgo de Ichcateopan. Dictamen que rinde la Comisión designada por acuerdo del C. Secretario de Educación Pública, en relación con las investigaciones y exploración realizadas en Ichcateopan, Guerrero, sobretiro del tomo undécimo de la Revista Mexicana de Estudios Antropológicos, México, 1950.

González Obregón, Luis

México viejo y anecdótico, México, Librería de la Viuda de Ch. Bouret, 1909.

Maza, Francisco de la

"Los restos de Hernán Cortés", en Cuadernos Americanos, 32 (mar.-abr. 1947), pp. 153-174.

Mier, Servando Teresa de

Historia de la revolución de Nueva España antiguamente Anábuac ó verdadero origen y causas de ella con la relación de sus progresos hasta el presente año de 1813, edición tomada literalmente de la primera del año 1813, México, Fuente Cultural, 1932, 2 vols.

Memoria politico instructiva enviada desde Filadelfia a los gefes independientes del Anábuac, llamado por los españoles Nueva España, México, 1822.

Reed Torres, Luis y José Manuel Villalpando César

Los restos de Don José María Morelos y Pavón. Itinerario de una búsqueda que aún no termina, México, Espejo de Obsidiana, 1993. 
Rueda, Salvador

"De conspiradores y mitógrafos: entre el mito, la historia y el hecho estético", en Historias, 39 (oct. 1997-mar. 1998), pp. 17-26.

Serrano Migallón, Fernando

El Grito de Independencia. Historia de una pasión nacional, México, Miguel Ángel Porrúa Editor, 1981.

Zavala Silvio

"Dictamen del doctor [...] sobre los manuscritos e inscripción del hallazgo de Ichcateopan”. 
